Rev. Elet. em Gestão, Educação e Tecnologia Ambiental (e-ISSN: 2236-1170)

\title{
DINÂMICA DA COBERTURA FLORESTAL NO MUNICÍPIO DE CRISSIUMAL-RS DURANTE UM PERÍODO DE VINTE ANOS
}

\author{
Diogo Belmonte Lippert ${ }^{1}$, Ana Caroline Benedetti ${ }^{2}$, Rudiney Soares Pereira ${ }^{3}$ \\ ${ }^{1}$ Programa de Pós Graduação em Engenharia Florestal da UFSM: diogo b lippert@hotmail.com, \\ ${ }^{2}$ Universidade Federal do Pampa - Unipampa, Campus São Gabriel: anaunipampa@gmail.com, \\ ${ }^{3}$ Universidade Federal de Santa Maria - UFSM: rudiney.s.pereira@gmail.com
}

\section{RESUMO}

O presente trabalho tem por objetivo avaliar a dinâmica da cobertura florestal do município de Crissiumal-RS, através de técnicas de sensoriamento remoto. A partir da classificação digital de imagens do satélite LANDSAT 5 sensor TM, dos anos de 1988 e 2008, foram gerados mapas temáticos do uso e cobertura da terra nas respectivas datas. Esses mapas foram posteriormente cruzados através da Linguagem Espacial para Geoprocessamento Algébrico (LEGAL), a qual possibilitou a determinação dos seguintes processos: manutenção florestal, regeneração florestal e desmatamento. Entre os principais resultados destacam-se o aumento na cobertura florestal em 4.756,33 ha e ainda a ocorrência de 1.508,04 ha de desmatamento no fim do período. $\mathrm{O}$ acréscimo na cobertura florestal pode estar associado à diminuição da população rural e ao abandono de áreas anteriormente ocupadas pela agricultura para o cumprimento da legislação vigente.

Palavras chave: uso da terra, análise temporal, cobertura florestal.

\section{ABSTRACT}

The present study aims to assess the dynamics of forest cover in Crissiumal-RS, through remote sensing techniques. From the digital classification of satellite images from Landsat 5 TM sensor, between 1988 and 2008 were generated thematic maps use and land cover on the respective dates. These maps were later crossed through the Space for GIS Algebraic Language (LEGAL), which allowed determination of the following processes: maintaining forest, forest regeneration and deforestation. Among the main results is the increase in forest cover in 4756.33 ha and also the occurrence of 1508.04 ha of deforestation at the end of the period. The increase in forest cover may be combined with declining rural population and the abandonment of areas previously occupied by agriculture to comply with the law.

Keywords: land use, temporal analysis, forest cover.

\section{INTRODUÇÃO}

No uso de técnicas disponíveis para analisar os compartimentos ambientais (físico, biótico e antrópico) de uma região, os Sistemas de Informação Geográfica (SIG) têm se mostrado uma ferramenta de grande importância para a integração de mapas temáticos, além de obterem dados e informações a respeito dos recursos naturais e das condições socioeconômicas (ASSAD e SANO, 
Rev. Elet. em Gestão, Educação e Tecnologia Ambiental (e-ISSN: 2236-1170)

1993; FERREIRA, 2002). A expressão "uso da terra" pode ser entendida como a forma pela qual o espaço está sendo ocupado pelo homem (ROSA, 1992), sendo assim, é importante considerar se o mesmo é explorado de forma organizada e produtiva.

SABINS (1999) comenta que, quando o mapeamento do uso da terra estiver associado aos SIG é possível conhecer a evolução da dinâmica espacial do uso e cobertura da terra com a produção de séries temporais de mapas de uma mesma área, afirmando serem essas informações essenciais para o planejamento da maioria das atividades, desenvolvidas em âmbito nacional, regional e municipal.

As imagens de satélite permitem uma visão sinóptica e multitemporal, o qual permite acompanhar as transformações do espaço ao longo do tempo, mostram-se como um eficiente mecanismo destinado a apresentar e interpretar alterações que ocorrem na superfície terrestre, tornando-se uma ferramenta de fundamental importância no apoio à decisão, em termos de conhecimento, planejamento e gestão do espaço.

A retirada das florestas e das vegetações nativas para a construção de infra-estrutura agrícola fraciona e reduz o espaço dos ecossistemas naturais, contribuindo para o assoreamento, o aumento da turbidez das águas, o desequilíbrio do regime das cheias, a erosão dos solos ocasionada devido às práticas incorretas de manejo dos solos, além do comprometimento da fauna silvestre, (OLIVEIRA-FILHO et al., 1994). A falta de planejamento e consequente destruição dos recursos naturais, particularmente das florestas caracterizam o processo de ocupação do Brasil. Ao longo da história do País, a cobertura florestal nativa, representada pelos diferentes biomas, foi sendo fragmentada, cedendo espaço para as culturas agrícolas, as pastagens e as construções das cidades (MARTINS, 2001).

Diante do dinamismo das ações humanas, não é possível acompanhar as transformações de forma rápida e atual sem auxílio de tecnologias, por isso, se faz necessário, o uso de técnicas e produtos do sensoriamento remoto, hoje disponíveis gratuitamente, que possibilitam obter de forma rápida e segura o levantamento e o mapeamento de uso e ocupação de porção do espaço geográfico. $O$ trabalho tem como objetivo avaliar a dinâmica da cobertura florestal do município de Crissiumal-RS, ocorrida entre duas datas distintas, 17/04/1988 e 08/04/2008 e ainda identificar e quantificar o uso e cobertura da terra por meio da classificação digital de imagens em um Sistema de informação Geográfica (SIG).

\section{MATERIAL E MÉTODOS}

\subsection{Localização e caracterização da área de estudo}

O município de Crissiumal está localizado entre as coordenadas geográficas $27^{\circ} 24^{\prime} 04^{\prime \prime}$ e $27^{\circ} 34^{\prime} 50^{\prime \prime}$ de latitude sul e $54^{\circ} 17^{\prime} 10^{\prime \prime}$ e $53^{\circ} 58^{\prime} 40^{\prime \prime}$ de longitude oeste e compreende uma área territorial de aproximadamente $399,5 \mathrm{Km}^{2}$. Pertence a zona fisiográfica do Alto Uruguai, que integra a unidade geomorfológica do Planalto Meridional Brasileiro (KAUL, 1992). Toda região apresenta altitudes elevadas variando entre 200 e 420 metros acima do nível do mar e relevo ondulado a fortemente ondulado.

As formações vegetais fazem parte da Floresta Estacional Subtropical, com inúmeras espécies arbóreas configuradas atualmente em remanescentes florestais muitas vezes associadas às áreas de regeneração. $\mathrm{O}$ clima é subtropical ( $\mathrm{Cfa}$ ), com temperaturas entre $-3^{\circ} \mathrm{C}$ a $18^{\circ} \mathrm{C}$ no mês 


\section{Rev. Elet. em Gestão, Educação e Tecnologia Ambiental (e-ISSN: 2236-1170)}

mais frio, e no mês mais quente superior a $10^{\circ} \mathrm{C}$ sem nenhuma estação seca definida (úmida todo ano) e verão quente, com temperatura média mensal superior a $22^{\circ} \mathrm{C}$ (MORENO, 1961).

Como aspectos geológicos, destaca-se a presença de rochas vulcânicas, pertencentes à formação da Serra Geral (HERMANN e ROSA, 1990). De acordo com o Sistema Brasileiro de Classificação de Solos (SBCS) no município aparecem as seguintes tipologias: Chernossolo Argilúvico e Neossolo Litólico (STRECK et al., 2002).

A economia do município é baseada no setor primário, onde as atividades agrícolas são responsáveis pela maior geração de renda do município. O sistema de minifúndio é predominante no município, sendo que a grande maioria das propriedades rurais tem áreas em torno de 20 hectares. A agricultura é diversificada, destacando-se os cultivos de soja, milho, trigo, mandioca e fumo e ainda pastagens plantadas para a criação intensiva de gado leiteiro.

\subsection{Materiais}

Os materiais utilizados nesse trabalho são os seguintes: aplicativo SPRING (Sistema para Processamento de Imagens Georreferenciadas) para processamento e análise; imagem TM satélite LANDSAT-5, com resolução espacial de 30 metros, bandas espectrais 1, 2, 3, 4, 5, e 7 órbita-ponto: WRS 223-079 de 17 de abril de 1988; imagem satélite LANDSAT-5, bandas espectrais 1, 2, 3, 4, 5 e 7 - órbita-ponto: WRS 223-079 de 08 de abril de 2008; cartas topográficas DSG na escala 1:50.000 e levantamento de reconhecimento de unidades de mapeamento dos solos do Estado do Rio Grande do Sul, escala 1:750.000.

\subsection{Metodologia}

Para o processamento e a análise foi inicialmente procedida a georreferência das cenas do sensor TM do satélite LANDSAT 5, referentes aos anos de 1988 e 2008, através da tomada de 15 pontos geográficos visíveis, respectivamente em cada imagem e na carta topográfica; foram escolhidas coordenadas ao longo da rede de drenagem e estradas.

Os pontos amostrais foram posteriormente selecionados para a verificação do erro de controle, quantificado em 0,7 pixels e 0,8 pixels respectivamente para as cenas de 1988 e 2008 . Após, elaborou-se as composições "falsa-cor" "B3G4R5" e "B2G3R4" pela associação das diferentes bandas espectrais do satélite, e aplicada às estas, a técnica de contraste linear, com o objetivo de facilitar a identificação dos diferentes padrões de uso e cobertura da terra presentes nas duas cenas.

Para a classificação digital supervisionada das imagens, foram identificadas áreas de treinamento representativas dos pixels de determinadas classes de uso e cobertura, para que cada pixel da imagem fosse classificado de acordo com a classe a que mais se assemelha.

O algoritmo usado nesse procedimento foi o MaxVer (Máxima Verossimilhança), de acordo com Venturiere e Santos (2003), esse é um dos métodos interativos de classificação mais utilizado por apresentar sob certos aspectos maior precisão na classificação. Essa forma de classificação adota a função de densidade probabilística, baseada na estatística bayesiana onde o classificador verifica a probabilidade de cada pixel em pertencer a determinada classe, englobando-a na de maior probabilidade. Para Mazza (2000), para que a classificação seja precisa, é necessário um número razoavelmente elevado de pixels para cada conjunto de treinamento.

A partir da análise das composições sintéticas falsa-cor, foram identificados diferentes padrões de uso da terra, sendo tomadas amostras representativas para o agrupamento conforme 
Rev. Elet. em Gestão, Educação e Tecnologia Ambiental (e-ISSN: 2236-1170)

as características (tabela 1) nas seguintes classes temáticas adotadas: floresta, campo, solo agrícola, lâmina d'água e área urbana.

Tabela 1. Chave de identificação dos padrões de uso e cobertura da terra nas bandas espectrais 2, 3, 4 e 5 do sensor TM do satélite Landsat 5, município de Crissiumal-RS em 17/04/1988 e 08/04/2008.

\begin{tabular}{ccccc}
\hline Amostra & Classes & Padrão B3G4R5 & Padrão B2G3R4 & Formato \\
\hline $\mathbf{0 1}$ & Floresta & Verde escuro & Vermelho escuro e claro & Irregular \\
$\mathbf{0 2}$ & Campo & Verde Claro/Amarelo & Róseo & Irregular \\
$\mathbf{0 3}$ & Solo & Róseo & Azul claro & Regular \\
$\mathbf{0 4}$ & Água & Azul & Cinza claro azulado & Irregular \\
$\mathbf{0 5}$ & Área Urbana & Lilás & Cinza claro & Regular \\
\hline
\end{tabular}

Para a análise da dinâmica florestal durante o período compreendido, procedeu-se o cruzamento do mapa de uso da terra de 2008 com relação ao mapa da data posterior (2008), através da Linguagem Espacial de Geoprocessamento Algébrico (LEGAL) do SPRING possibilitou a consulta e manipulação espacial dos dados obtidos pela classificação digital. Essa linguagem espacial provê um ambiente geral para análise geográfica, com operadores espaciais sobre geocampos e geo-objetos existentes no banco de dados (CÂMARA, 1995).

Na programação em linguagem LEGAL são utilizados esquemas conceituais para definir a espacializações das classes do modelo de dados. No editor de modelos foram realizados os cruzamentos a partir dos algoritmos bayesianos de intercessão sendo possível a identificação dos processos de manutenção, desmatamento e regeneração florestal durante o período de vinte anos.

\section{RESULTADOS E DISCUSSÃO}

\subsection{Mapas de uso e cobertura da terra}

Os mapas de uso e cobertura (figura 1) foram obtidos pela classificação digital das cenas Landsat dos anos de 1988 e 2008; a análise das amostras tomadas nas imagens e os resultados da classificação foram avaliados através do coeficiente Kappa. Segundo Congalton e Green (1999), esse coeficiente é baseado na diferença entre a concordância observada (diagonal principal da matriz de confusão com a concordância entre a classificação e os dados de referência) e a chance de concordância entre os dados de referência e uma classificação aleatória (produto entre as totais marginais da matriz de classificação). O valor de Kappa é calculado pela equação a seguir:

$$
K=\frac{N \sum_{i=1}^{r} x_{i i}-\sum_{i=1}^{r}\left(x_{i+} x_{+i}\right)}{N^{2}-\sum_{i=1}^{r}\left(x_{i+} x_{+i}\right)}
$$

Onde:

$r=$ Número de classes;

$\boldsymbol{x i i}=$ Número de elementos classificados corretamente;

$\boldsymbol{x i +}=$ Total de elementos classificados para uma categoria $i$;

$\boldsymbol{x}+\boldsymbol{i}=$ Total de elementos de referência amostrados para uma categoria i; $\boldsymbol{N}=$ Número total de amostras. 
Rev. Elet. em Gestão, Educação e Tecnologia Ambiental (e-ISSN: 2236-1170)

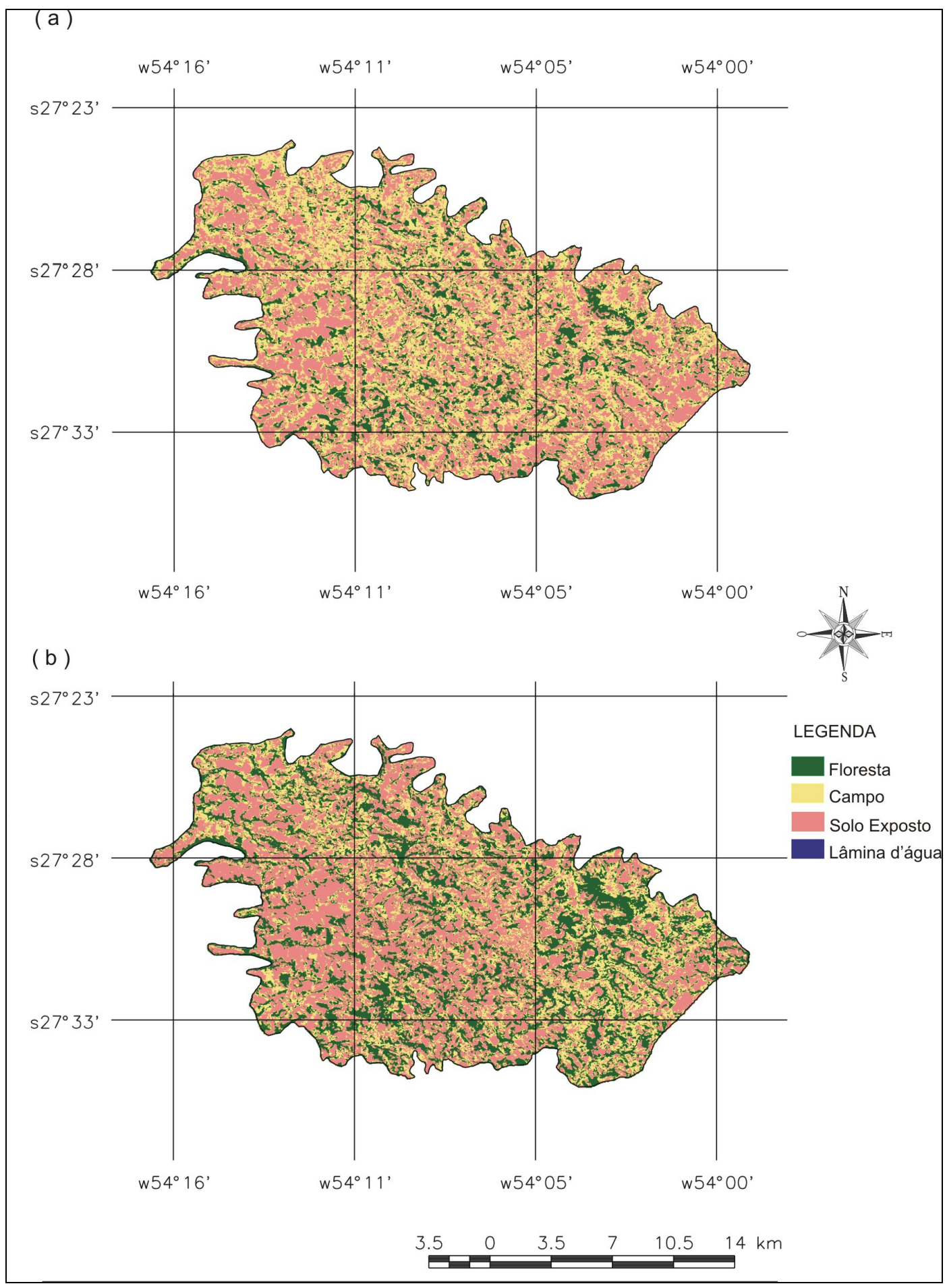

Figura 1. Mapas de uso e cobertura da terra em abril de 1988 (a) e abril de 2008(b) no município de Crissiumal-RS.

Landis e Koch (1977) propõem uma escala de avaliação da qualidade da classificação para a análise do coeficiente Kappa como descrito na tabela 2.

Tabela 2. Qualidade da classificação segundo intervalos do coeficiente Kappa. 
Rev. Elet. em Gestão, Educação e Tecnologia Ambiental (e-ISSN: 2236-1170)

\begin{tabular}{cc}
\hline Valor Kappa & Qualidade da classificação \\
\hline$<0,00$ & Péssima \\
$0,00-0,20$ & Ruim \\
$0,20-0,40$ & Razoável \\
$0,40-0,60$ & Boa \\
$0,60-0,80$ & Muito Boa \\
$0,80-1,0$ & Excelente \\
\hline
\end{tabular}

Fonte: Landis e Koch (1977).

Os valores obtidos para as classificações digitais de 1988 e 2008 foram os seguintes:

$$
\begin{aligned}
& K=\frac{(41149 \times 4083)-7350943}{(4119)^{2}-7350943}=0,9846 \\
& K=\frac{(5144 \times 4983)-9215510}{(5144)^{2}-9215510}=0,9520
\end{aligned}
$$

Os resultados obtidos pelo índice Kappa das amostras de treinamento usadas na classificação digital são considerados excelentes. Os valores de desempenho médio obtidos foram de $99,13 \%$ e $96,87 \%$ para as duas datas analisadas. Esses valores confirmam a ocorrência de mudanças substanciais durante o período de estudo. A tabela 3 apresenta os valores obtidos para os dois mapas de uso e cobertura da terra.

Tabela 3. - Ocupação das classes de uso e cobertura da terra no município de Crissiumal em abril de 1988 e em abril de 2008.

\begin{tabular}{cccc}
\hline Classe de uso & Área em 1988 (ha) & Área em 2008 (ha) & $\begin{array}{c}\text { Dinâmica entre 1988 e } \\
\text { 2008 (ha) }\end{array}$ \\
\hline floresta & 6832,62 & 11589,15 & $+4756,33$ \\
solo exposto & 16945,56 & 16789,77 & $-20,69$ \\
campo & 15712,2 & 11135,54 & $-4756,66$ \\
lâmina d'água & 33,84 & 9,75 & $-24,09$ \\
área urbana & 213,39 & 213,39 & 0 \\
\hline
\end{tabular}

Na classe "floresta" estão agrupadas as formações vegetais arbóreas primárias (vegetação pioneira) e secundárias presentes muitas vezes ao longo de canais fluviais, nas encostas de morros e na forma de pequenos capões, que tiveram um acréscimo de 4.756,33 ha no fim do período. A classe "solo exposto" refere-se a áreas agrícolas que nessa época do ano encontra-se, em sua maioria, em pousio ou fase de preparo do solo; quantificou-se uma redução de 20,69 ha durante o período. Essa classe compreende pequenas áreas de pastagem cultivadas ou nativas, podendo apresentar vegetação rasteira, usadas para a criação intensiva de bovinos como também podem pertencer a essa classe, pequenos cultivos agrícolas, sendo que na última análise verificou-se a redução de 4.756,66 ha.

As lâminas d'água são pouco expressivas no interior do município, sendo pequenos açudes nas propriedades rurais muitas vezes com área incompatível com a resolução espacial de 30 metros das imagens. Foi quantificada nessa classe, uma diminuição de 24,09 ha no fim do período. Esse fato pode ser explicado em parte pelo aumento da vegetação nativa ao longo dos canais fluviais, o que dificulta a interpretação desta classe na rede drenagem. Para a quantificação 
Rev. Elet. em Gestão, Educação e Tecnologia Ambiental (e-ISSN: 2236-1170)

da área urbana do município foi construído um polígono vetorial, a partir do qual se realizou a intercessão pela análise LEGAL para a determinação correta dos valores das demais classes de uso.

\subsection{Mapa de dinâmica da cobertura florestal}

A dinâmica da cobertura florestal pode ser avaliada através da análise LEGAL aplicada entre os mapas temáticos de 1988 e 2008; a figura 2 demonstra os resultados para as novas classes consideradas: Desmatamento (locais em que havia cobertura florestal e posteriormente encontram-se com outros usos) Regeneração florestal (locais em que a cobertura florestal foi estabelecida na data posterior) e Manutenção florestal (áreas de permanência de florestas).

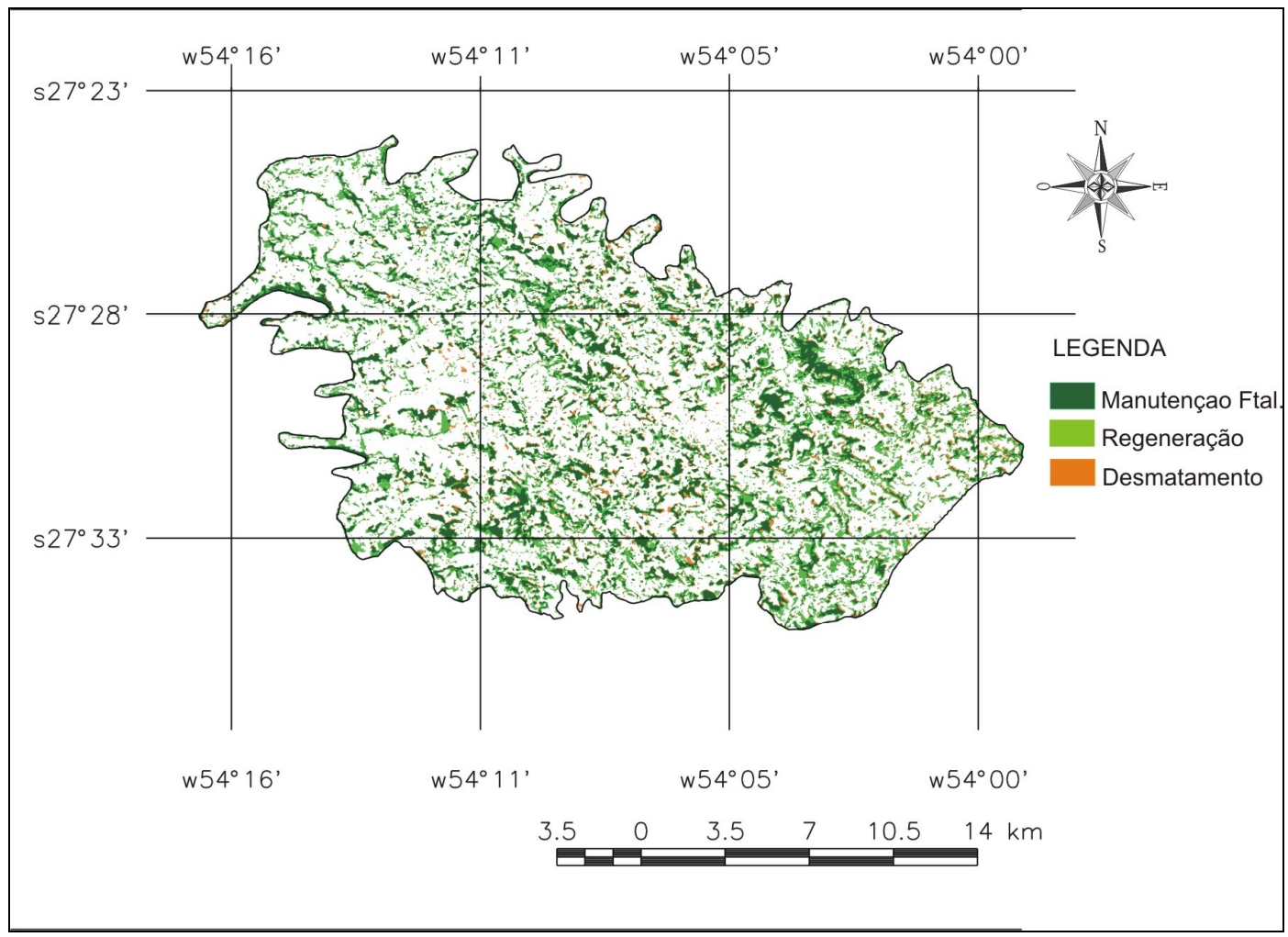

Figura 2. Mapa da dinâmica florestal entre 1988 e 2008 no município de Crissiumal-RS.

Os desmatamentos totalizam 1.508,04 ha e ocorrem em áreas atualmente ocupadas por atividades agrícolas; com isso, observa-se que essa classe não apresenta uma área expressiva com relação às demais classes analisadas; esse fato pode estar associado à diminuição da população rural ao longo dos anos e o conseqüente abandono de áreas agrícolas; o que comprova também uma regeneração florestal quantificada em 6.271,28 ha ao final do período.

A cobertura florestal apresentou uma distribuição espacial superior em todo o município; o acréscimo em área florestal dá-se pelo aumento do tamanho dos fragmentos florestais remanescentes observados em abril de 1988 e também pelo surgimento de vegetação pioneira em espaços anteriormente agrícolas. Parte da cobertura florestal deve-se ao plantio de florestas comerciais, principalmente dos gêneros Eucalyptus e Pinus, o qual vem aumentado na região em função da demanda de tal matéria prima. A manutenção florestal totalizou 5.330,42 ha, essas áreas permaneceram inalteradas em locais íngremes e impróprios para a agricultura e algumas 
Rev. Elet. em Gestão, Educação e Tecnologia Ambiental (e-ISSN: 2236-1170)

vezes ao longo da rede drenagem, no entanto, verifica-se que ao longo de 20 anos, em parte das matas ciliares, não houve reposição ou conservação.

\section{CONCLUSÃO}

A análise da dinâmica no município de Crissiumal no período de vinte anos, com relação aos usos floresta, solo exposto, campo e lâmina d'água, possibilitou verificar um acréscimo das áreas florestais e conseqüente redução de áreas agrícolas. Tal fato pode estar diretamente relacionado ao êxodo rural, aos novos processos de ocupação das atividades agrícolas as quais mudaram com o avanço tecnológico e a introdução de novas culturas, como também, podem estar influenciados até mesmo, pelo cumprimento da legislação ambiental vigente.

\section{REFERÊNCIAS BIBLIOGRÁFICAS}

ASSAD, E. D; et al. Estruturação de dados geoambientais no contexto de sub-bacia hidrográfica. In: ASSAD, E. D; SANO, E. E. (Ed.). Sistema de informações geográficas: aplicações na agricultura. 2.ed. Brasília: Embrapa

- SPI, 1998. p. 119-158.

CÂMARA, G. Modelos, Linguagens e Arquiteturas para Bancos de Dados Geográficos. 1995. 282f. Tese (Doutorado em Computação Aplicada) - Instituto Nacional de Pesquisas Espaciais, São José dos Campos, 1995.

CONGALTON, Russel G.; GREEN, Kass Assessing the accuracy of remotely sensed data: principles and practices. New York: Lewis Publishers, 1999. 1990.

HERRMANN, M. L. P.; ROSA, R. O. Relevo e Geografia do Brasil. Rio de Janeiro: IBGE,

KAUL, P. F. T. Geologia. Geografia do Brasil: Região Sul. Rio de Janeiro: Ed. Sergraf, FIBGE, 1992. p. 29-54.

LANDIS, J.; KOCH, G. G. The measurements of agreement for categorical data. Biometrics, Washington, v. 33, n. 3, p. 159-179, Mar. 1977.

MARTINS, Sebastião Venâncio. Recuperação de Mata Ciliar. Viçosa: Aprenda Fácil, 2001.

MAZZA, C. A. S. Distribuição espacial da bracatinga na região metropolitana de Curitiba com imagens de satélite Landsat. Colombo: Embrapa Florestas, 2000. 23p. (Documentos, 44).

MORENO, J. A. Clima do Rio Grande do Sul. Porto Alegre: Secretaria da Agricultura, 1961.

OLIVEIRA-FILHO, A. T.; ALMEIDA, R. J. de; MELLO, J.M. de; GAVILANES, M.L. Estrutura fitossociológica e variáveis ambientais em um trecho de mata ciliar do córrego Vilas Boas, 
Rev. Elet. em Gestão, Educação e Tecnologia Ambiental (e-ISSN: 2236-1170)

Reserva Biológica do Poço Bonito, Lavras (MG). Revista Brasileira de Botânica, São Paulo, v.17, n.1, p.67-85, 1994.

ROSA, R. Introdução ao Sensoriamento Remoto. 2a ed.rev. Uberlândia. Ed. da Universidade Federal de Uberlândia, 1992.

SABINS, F.F. Remote Sensing: principles and interpretation. 3. rd. New York: W. F. Freeman and Company, 1999. 494p.

SHUMACHER, M. V.; LONGHI, S. J.; BRUN, E. J.; KILCA, R. V. A Floresta Estacional Subtropical: Caracterização e Ecologia no Rebordo do Planalto Meridional. 1 ed. Santa Maria: Palotti, v. 1. 2001.

STRECK, Edemar V.; KAMPF, Nestor; DALMOLIN, Ricardo S. D.; KLAMT, Egon; NASCIMENTO, Paulo C.; SCHNEIDER, P. Solos do Rio Grande do Sul. Porto Alegre: EMATERRS/UFRGS, 2002.

VENTURIERE, A.; SANTOS, J.R. dos. Técnicas de classificação de imagens para análise da cobertura vegetal. In: ASSAD, E. D. \& SANO, E. E. (Org.). 